Supplementary Information

\title{
A Dual-Response Ratiometric Electrochemical Microsensor for Effectively Simultaneous Monitoring of Hypochlorous Acid and Ascorbic Acid in Human Body Fluids
}

Hui Dong ${ }^{a, b}$, Yanli Zhou ${ }^{a, *}$, Le Zhao ${ }^{a}$, Yuanqiang Hao ${ }^{a}$, Yintang Zhang ${ }^{a}$, Baoxian $\boldsymbol{Y e}^{b}$, Maotian $\mathrm{X} \boldsymbol{u}^{a, b, *}$

${ }^{a}$ Henan Key Laboratory of Biomolecular Recognition and Sensing, College of Chemistry and Chemical Engineering, Henan Joint International Research Laboratory of Chemo/Biosensing and Early Diagnosis of Major Diseases, Shangqiu Normal University, Shangqiu 476000, Henan Province, PR China

${ }^{b}$ College of Chemistry and Molecular Engineering, Zhengzhou University, Zhenghou 450001, Henan Province, PR China

*Corresponding author. E-mail: xumaotian@163.com, zhouyanli@mails.ucas.ac.cn 


\section{Table of contents:}

1. Experimental section.

2. Electrochemical Characterization of the Modified Electrodes.

3. ${ }^{1} \mathrm{H}$ NMR and ${ }^{13} \mathrm{C}$ NMR and mass spectra of MBS (Figure S1).

4. UV-Vis absorption spectra of GO and GO-CNT (Figure S2).

5. Electrochemical reduction of CFME/GO-CNT (Figure S3).

6. XPS data (Figure S4).

7. CV and EIS (Figure S5).

8. DPV responses for $\mathrm{AA}$ at different modified electrodes (Figure S6).

9. DPVs obtained at CFME/ERGO-CNT/AQ (Figure S7).

10. UV-Vis absorption spectral response of probe MBS to HClO (Figure S8).

11. Response time (Figure S9).

12. Liquid chromatography (Figure S10).

13. Mass spectra of MB (Figure S11).

14. Reaction mechanism of MBS and HClO (Figure S12).

15. DPVs obtained at CFME/ERGO-CNT/MBS(Figure S13).

16. Comparison of DPV responses of different modified electrodes to AA and HCIO (Figure S14).

17. pH effect (Figure S15).

18. Scan rate (Figure S16).

19. UV-Vis absorption spectral response of AA to HClO (Figure S17).

20. Time dependent UV-Vis absorption response of AA to $\mathrm{HClO}$ (Figure S18).

21. Selectivity and competition tests (Figure S19).

22. DPVs obtained at CFME/ERGO-CNT/AQ+MBS for different concentrations of $\mathrm{HClO}$ (Figure S20)

23. Contact angles (Figure S21).

24. Reproducibility and repeatability (Figure S22).

25. Stability (Figure S23).

26. Biocompatibility(Figure S24).

Table S1. The concentrations of $\mathrm{HClO}$ and AA determined by the present method in Urine.

Table S2. AA detection at CFME/ERGO-CNT/AQ+MBS electrode in human serum with AD.

Table S3. The concentrations of $\mathrm{HClO}$ and AA determined by the present method in saliva. 


\section{Experimental section}

1.1 Preparation of Various ROS and RNS Solutions. ${ }^{1}$ A $7.5 \% \mathrm{NaOCl}$ solution in $0.1 \mathrm{M} \mathrm{NaOH}$ was used to prepare $\mathrm{HClO}$. The concentration of $\mathrm{HClO}$ was based on its molar extinction coefficient at $292 \mathrm{~nm}\left(350 \mathrm{M}^{-1} \mathrm{~cm}^{-1}\right)$. The reaction between $\mathrm{Fe}^{2+}$ and $\mathrm{H}_{2} \mathrm{O}_{2}\left(1: 6 \mathrm{Fe}^{2+} / \mathrm{H}_{2} \mathrm{O}_{2}\right)$ produced hydroxyl $(\bullet \mathrm{OH})$ radicals in concentrations equal to that of $\mathrm{Fe}^{2+}$. Superoxide anions $\left(\mathrm{O}_{2}{ }^{-}\right)$were derived from $\mathrm{KO}_{2}(20 \mu \mathrm{M})$ dissolved in

DMSO. Nitric oxide (NO) was produced by dissolving $S$-nitroso- $N$-acetylpenicillamine $(1 \mathrm{mM})$ in $0.1 \mathrm{M}$ phosphate-buffered saline (PBS, pH 6.5). A peroxynitrite $\left(\mathrm{ONOO}^{-}\right)$solution was prepared from $\mathrm{KNO}_{2}(0.6 \mathrm{M})$ and $\mathrm{H}_{2} \mathrm{O}_{2}$ $(0.7 \mathrm{M})$ in $0.6 \mathrm{M} \mathrm{HCl}$ at $0{ }^{\circ} \mathrm{C}$ and stored at $-20^{\circ} \mathrm{C}$.

1.2 Apparatus and Measurements. ${ }^{1} \mathrm{H}$ NMR and ${ }^{13} \mathrm{C}$ NMR spectra were recorded on a $400 \mathrm{MHz}$ NMR spectrometer (Bruker, USA). The chemical shifts $(\delta)$ were reported downfield from the $\mathrm{Me}_{4} \mathrm{Si}$ internal reference. High-performance liquid chromatography-mass spectrometry (HPLC-MS) was performed with a Bruker solan X 70 FT-MS system with 6540TOF detectors using electrospray ionization as an ion source (Bruker, USA). Separation was performed using a $4.6 \times 250 \mathrm{~mm}(5 \mu \mathrm{m}) \mathrm{C} 18$ column (Agilent, Santa Clara, USA). Ultraviolet-visible (UV-vis) spectra were obtained using a Lambda565 UV-vis spectrophotometer (PerkinElmer, USA). Scanning electron microscope (SEM) images were obtained using a S-4800 field emission SEM (Hitachi, Japan) operated at $4 \mathrm{kV}$. Electron spectroscopy for chemical analysis was performed using a PHI 5000 X-ray photoelectron spectrometer (XPS, Perkin Elmer, USA) equipped with a monochromatic $\mathrm{Mg} \mathrm{K} \alpha$ source ( $\mathrm{h} v=1253.6$ 
$\mathrm{eV})$.

A CHI660D electrochemical workstation (Shanghai CH Instruments, China) was used for electrochemical analysis. Cyclic voltammetry $(\mathrm{CV})$ and differential pulse voltammetry (DPV) were performed using a three-electrodes cell system. A modified CFME/ERGO-CNT/AQ+MBS microelectrode served as the working electrode. An $\mathrm{Ag} / \mathrm{AgCl}$ electrode fabricated in-house and a platinum wire served as the reference and counter electrodes, respectively. Unless otherwise noted, DPV was performed over the potential range from -0.70 to $0.20 \mathrm{~V}$ with a potential step of $4 \mathrm{mV}$ and a modulation amplitude of $50 \mathrm{mV}$. The pulse width and pulse period were $0.05 \mathrm{~s}$ and $0.4 \mathrm{~s}$, respectively. All electrochemical measurements were performed at room temperature.

1.3 Preparation of CFME. CFMEs were prepared as described in our previous reports. ${ }^{2,3}$ Briefly, carbon fibers with diameters of $7 \mu \mathrm{m}$ (Tokai Carbon Co., Tokai, Japan) were affixed to copper wires using conductive silver paint and dried in air. The affixed fibers were carefully threaded into pulled glass capillary tubes. Both ends of each capillary tube were sealed with a 1:1 mixture of epoxy resin and ethylendiamine. Acetone was used to carefully remove the excess epoxy resin from the fibers, and the carbon fiber microelectrodes were dried overnight at $100{ }^{\circ} \mathrm{C}$. The exposed carbon fibers were cut to lengths of $\sim 500 \mu \mathrm{m}$ under a microscope. Prior to modification, the fabricated CFMEs were sonicated sequentially in acetone, $3.0 \mathrm{M} \mathrm{HNO}_{3}, 1.0 \mathrm{M} \mathrm{KOH}$, and distilled water for 3 min each.

1.4 Preparation of graphene oxide (GO). GO was synthesized from graphite 
powder using the modified Hummers method. ${ }^{4} \mathrm{KMnO}_{4}(15 \mathrm{~g})$ and $\mathrm{NaNO}_{3}(2.5 \mathrm{~g})$ were added separately to concentrated $\mathrm{H}_{2} \mathrm{SO}_{4}(98 \%, 115 \mathrm{~mL})$ in a $1,000 \mathrm{~mL}$ beaker with continuous stirring over an ice bath, and the graphite powder $(2.5 \mathrm{~g})$ was added to the beaker slowly. The reaction was allowed to proceed overnight, after which the mixture was held at $37{ }^{\circ} \mathrm{C}$ in a water bath for $30 \mathrm{~min}$. Distilled water $(230 \mathrm{~mL})$ was added slowly with stirring, and the temperature was maintained at $98{ }^{\circ} \mathrm{C}$ for $30 \mathrm{~min}$. An additional $100 \mathrm{~mL}$ of deionized water was added to the beaker to stop the reaction. A $30 \% \mathrm{H}_{2} \mathrm{O}_{2}$ solution $(30 \mathrm{~mL})$ was added to the suspension, and its color went from brown to yellow. The suspension was repeatedly washed with an aqueous $5 \% \mathrm{HCl}$ solution and DI water until the $\mathrm{pH}$ was neutral. Deionized water was then added, and the oxidized mixture was ultrasonicated for $5 \mathrm{~h}$ to fully convert graphite oxide to graphene oxide. The mixture was centrifuged at $10,000 \mathrm{rpm}$ for $10 \mathrm{~min}$, and the supernatant was carefully separated from the bottom sediment. A transparent yellow-brown graphene oxide solution with a concentration of $\sim 0.5 \mathrm{mg} \mathrm{mL}^{-1}$ was collected and reserved for subsequent experiments.

1.5 Synthesis of MBS. Briefly, dichloromethane $(10 \mathrm{~mL})$ and $\mathrm{Na}_{2} \mathrm{CO}_{3}(1.59 \mathrm{~g}$, $15.00 \mathrm{mmol}$ ) were added to $5 \mathrm{~mL}$ of an aqueous $\mathrm{MB}$ solution $(1.12 \mathrm{~g}, 3.75 \mathrm{mmol})$, and the mixture was stirred at $40{ }^{\circ} \mathrm{C}$ under $\mathrm{N}_{2}$. Then $\mathrm{Na}_{2} \mathrm{~S}_{2} \mathrm{O}_{3}(2.61 \mathrm{~g}, 15.00 \mathrm{mmol})$ was dissolved in $10 \mathrm{~mL}$ water and injected into the mixture using a syringe. The solution became yellow in color, and the dichloromethane layer was separated from the aqueous layer and quickly dried over anhydrous sodium sulfate without further purification. The solution was then added dropwise to a mixture of DMAP (0.46 g, 
$3.75 \mathrm{mmol}), \mathrm{Na}_{2} \mathrm{CO}_{3}(1.19 \mathrm{~g}, 11.25 \mathrm{mmol})$ in $5 \mathrm{~mL}$ dry dichloromethane, and isobutyryl chloride $(3.75 \mathrm{mmol})$ in an ice water bath. The mixture was stirred at room temperature and monitored via thin-layer chromatography until the reaction was complete. The undissolved solids were removed via filtration, and the solution was dried to a solid residue using a rotary evaporator. The crude product was purified on a flash column using 1:10 ethyl acetate/petroleum as an eluent, and the MBS product was obtained as a white solid in a $30 \%$ yield (400 mg). The following ${ }^{1} \mathrm{H}$ NMR signals $(\delta)$ were detected at $400 \mathrm{~Hz}$ after dissolving the solid in $\mathrm{CDCl}_{3}: 7.17(\mathrm{~d}, 2 \mathrm{H})$, $6.63(\mathrm{~d}, 2 \mathrm{H}), 6.53(\mathrm{~m}, 2 \mathrm{H}), 2.97(\mathrm{dd}, 1 \mathrm{H}), 2.83(\mathrm{~d}, 12 \mathrm{H})$, and $0.86(\mathrm{~m}, 6 \mathrm{H})$. The calculated high-resolution (HR-MS) m/z for $\mathrm{C}_{20} \mathrm{H}_{26} \mathrm{~N}_{3} \mathrm{OS}[\mathrm{M}+\mathrm{H}]^{+}$was 356.1791, and the ion used for quantitation had an $\mathrm{m} / \mathrm{z}$ of 356.1797 (Figure $\mathrm{S} 1$ ).

1.6 Samples Preparation. Body fluids were collected from volunteers in our laboratory and serums from Alzheimers disease (AD) patients provided by Center Hospital of Shangqiu. Saliva samples from healthy volunteers $(n=3)$ samples were collected from each volunteer with an empty stomach in the morning on 3 nonconsecutive days) by using collection devices, which consists of a cotton swab that was chewed by the volunteer for $2 \mathrm{~min}$. To provide clear saliva samples for the experiments, the samples were suffered from centrifuging at 1,000 rpm for $1 \mathrm{~min}$ to remove food particles, impurities, and mucus. Prior to blood sample collection, $12 \mathrm{~h}$ urine samples were preferentially collected in clean bottles, and thereafter the blood samples were taken from the patients immediately, then $500 \mu \mathrm{L}$ of plasma and serum was centrifuged at $14,000 \mathrm{rpm}$ for $10 \mathrm{~min}$. The filtrate was collected for experiments. 
All collected samples, including treated saliva, urine, serum were diluted with 0.1 PBS ( $\mathrm{pH} 7.0)$ and measured by DPV in 0.1 M PBS ( $\mathrm{pH} 7.0)$. The spike recovery experiments were completed by adding different concentrations of $\mathrm{HClO}$ or AA stock solutions in $0.1 \mathrm{PBS}(\mathrm{pH} 7.0)$.

\section{Electrochemical Characterization of the Modified Electrodes.}

$\mathrm{CV}$ curves of the modified CFMEs in $1 \mathrm{mM} \mathrm{K}_{3} \mathrm{Fe}(\mathrm{CN})_{6}$ (Figure S5A) were firstly recorded at a scan rate of $0.10 \mathrm{~V} \mathrm{~s}^{-1}$. For the bare CFME, small peaks and low peak current density were observed, and the area under the curve was small. After the modification with GO and CNTs, the peak current enhanced. As expected, the peak current of CFME/ERGO-CNT electrode had a further increase, and the peak potential difference $(\Delta \mathrm{Ep})$ was significantly lower. This indicated that highly reversible redox reactions took place on the CFME/ERGO-CNT electrode, which could be attributed to a strong synergetic effect from ERGO and the CNTs. The modification process of microelectrodes were further characterized by performing electrochemical impedance spectroscopy (EIS). Since the charge transfer resistance $\left(\mathrm{R}_{\mathrm{ct}}\right)$ of the CFMEs was large and it is not convenient for the observation of the change ${ }^{5}$, GCE replaced CFME as the substrate for the EIS measurements. In Figure S5B (SI), the real and imaginary parts of the EIS spectra of bare GCE and the GCE/GO-CNT, GCE/ERGO-CNT, and GCE/ERGO-CNT/AQ+MBS electrodes are presented as Nyquist plots using $5 \mathrm{mM}$ $[\mathrm{Fe}(\mathrm{CN}) 6]^{3-/ 4-}$ as the electrolyte. The Randles equivalent circuit model was used to fit the experimental data (SI, inset of Figure S5B). $\mathrm{R}_{\mathrm{S}}$ is the resistance of the electrolyte solution, and $\mathrm{R}_{\mathrm{ct}}$ is the charge transfer resistance. $\mathrm{C}_{\mathrm{dl}}$ denotes the double layer 
capacitance, and $Z_{w}$ is the Warburg impedance. The $R_{c t}$ value of the GCE/GO-CNT electrode was lower than that of bare GCE. This clearly indicated that the CNTs were firmly attached to the GO surface in the GO-CNT hybrid material, which facilitated the electron transfer. Furtherfore, the $\mathrm{R}_{\mathrm{ct}}$ value of the GCE/ERGO-CNT electrode was significantly lower. This confirmed that ERGO-CNT had excellent electrochemical properties that enhanced conductivity and promoted electron transfer. However, the semicircle in the Nyquist plot of the GCE/ERGO-CNT/AQ+MBS microelectrode was much larger than the semicircle in the GCE/ERGO-CNT electrode plot. This indicated that the GCE/ERGO-CNT/AQ+MBS microelectrode was prepared successfully. 


\section{3. ${ }^{1} \mathrm{H}$ NMR and ${ }^{13} \mathrm{C}$ NMR and mass spectra of MBS.}
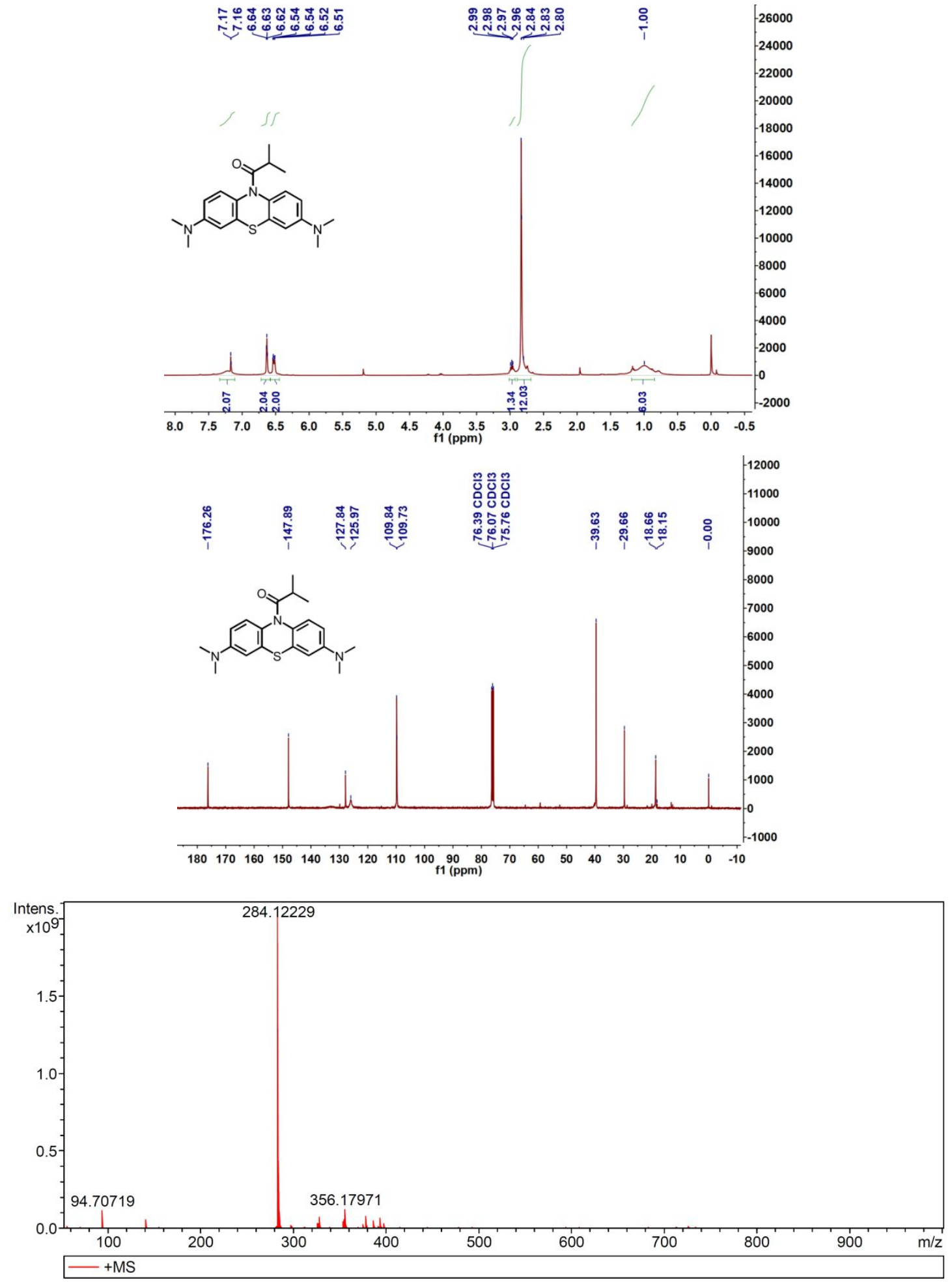

Figure S1. ${ }^{1} \mathrm{H}$ NMR, ${ }^{13} \mathrm{C}$ NMR and mass spectrum of MBS. 
4. UV-Vis absorption spectra of GO and GO-CNT.

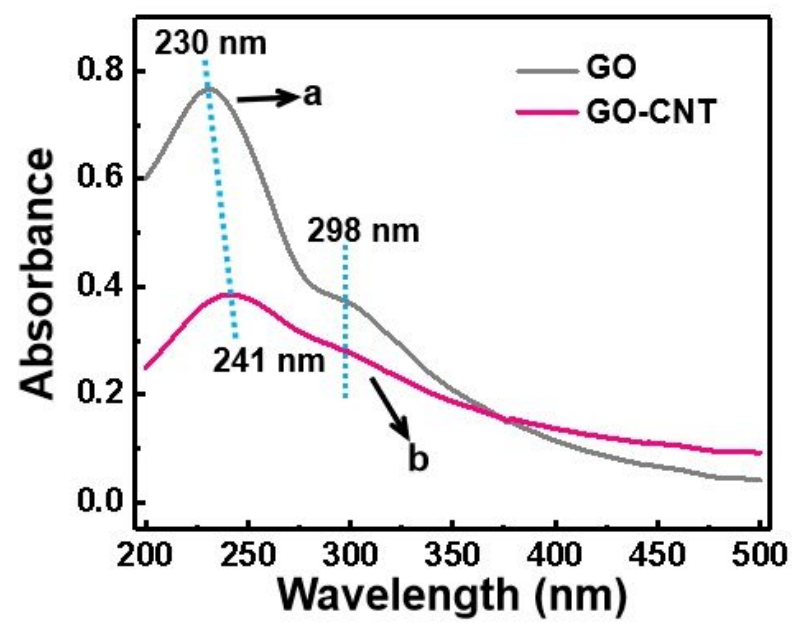

Figure S2. The UV-Vis absorbance spectra of $50 \mu \mathrm{g} \mathrm{mL}^{-1} \mathrm{GO}$ (a) and GO-CNT (b) in aqueous solution.

5. Electrochemical reduction of CFME/GO-CNT.

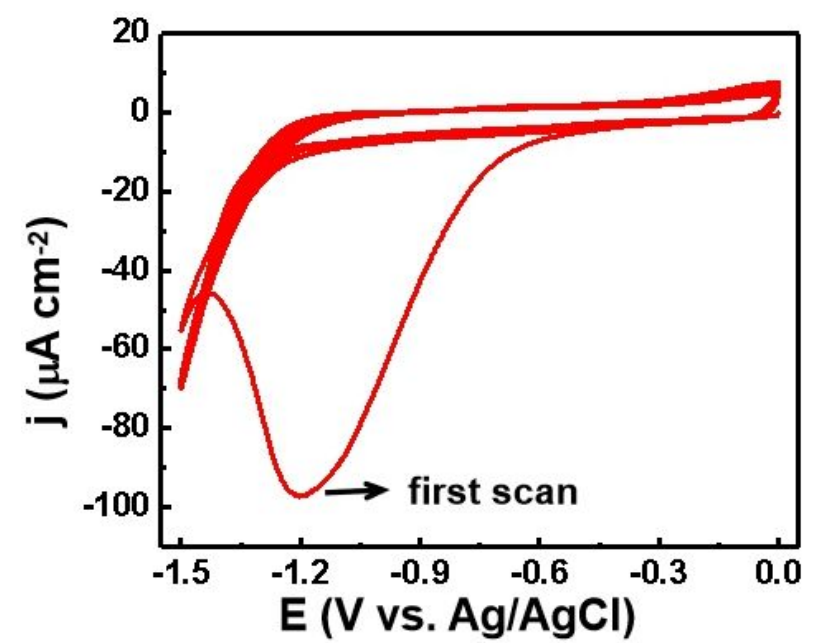

Figure S3. Electrochemical reduction of CFME/GO-CNT for 10 cycles in $0.1 \mathrm{M}$ PBS (pH 4.5). 


\section{XPS data.}
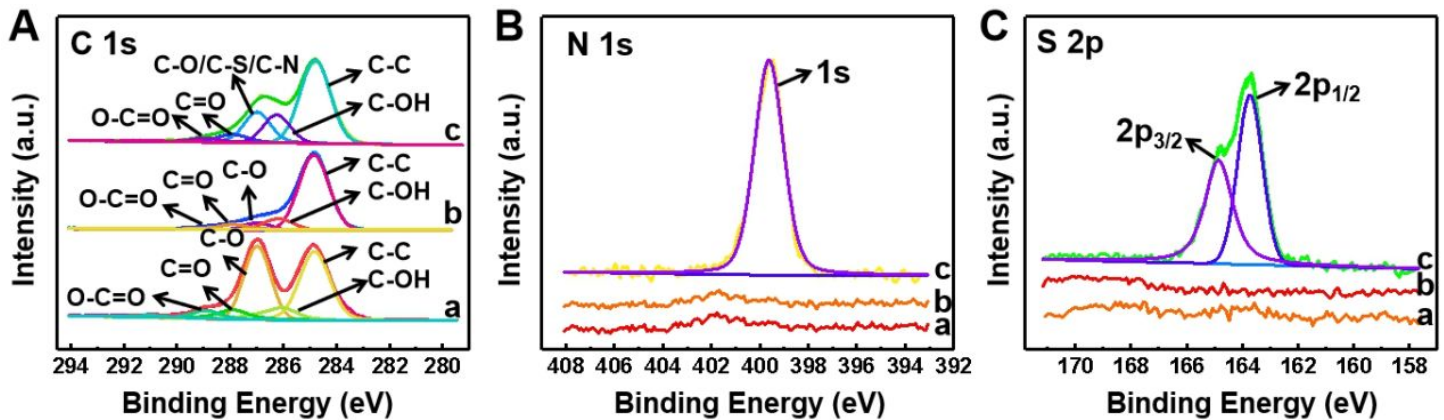

Figure S4. XPS spectra for (A) $\mathrm{C} 1 \mathrm{~s}$, (B) $\mathrm{N} 1 \mathrm{~s}$, (C) $\mathrm{S} 2 \mathrm{p}$ at (a) CFME/GO-CNT, (b) CFME/ERGO-CNT, (c) CFME/ERGO-CNT/AQ+MBS.

\section{CV and EIS Characterization of different Modified electrodes.}
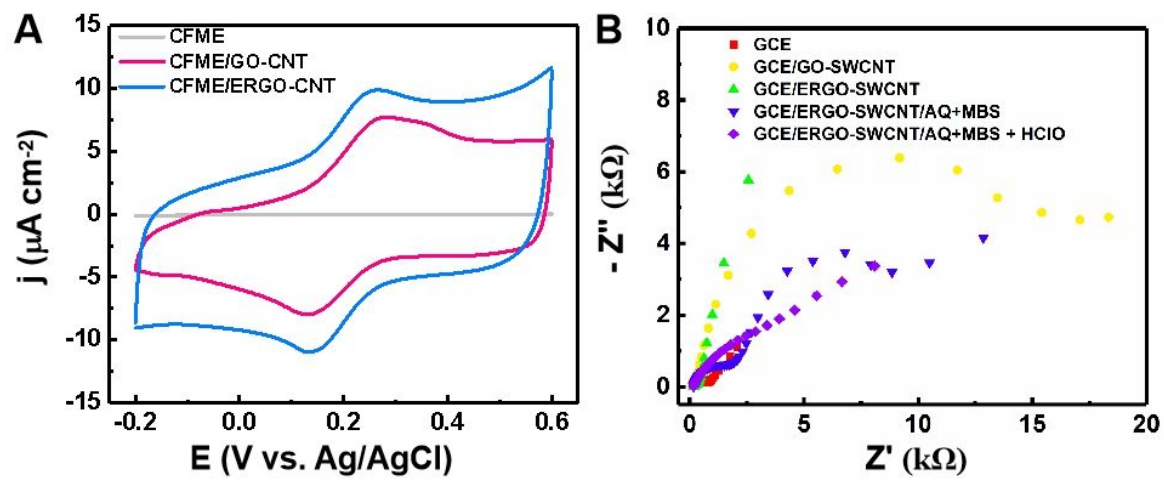

Figure S5. (A) CV curves of the modified electrodes in a $1 \mathrm{mM} \mathrm{K}_{3}\left[\mathrm{Fe}(\mathrm{CN})_{6}\right]$ solution containing $0.1 \mathrm{M} \mathrm{KCl}$. (B) EIS (Nyquist plots) of different modified electrodes in an aqueous solution containing $0.1 \mathrm{M} \mathrm{KCl}$ and $5 \mathrm{mM}\left[\mathrm{Fe}(\mathrm{CN})_{6}\right]^{3-/ 4-}(1: 1)$. 


\section{DPV responses for $\mathrm{AA}$ at different modified electrodes.}

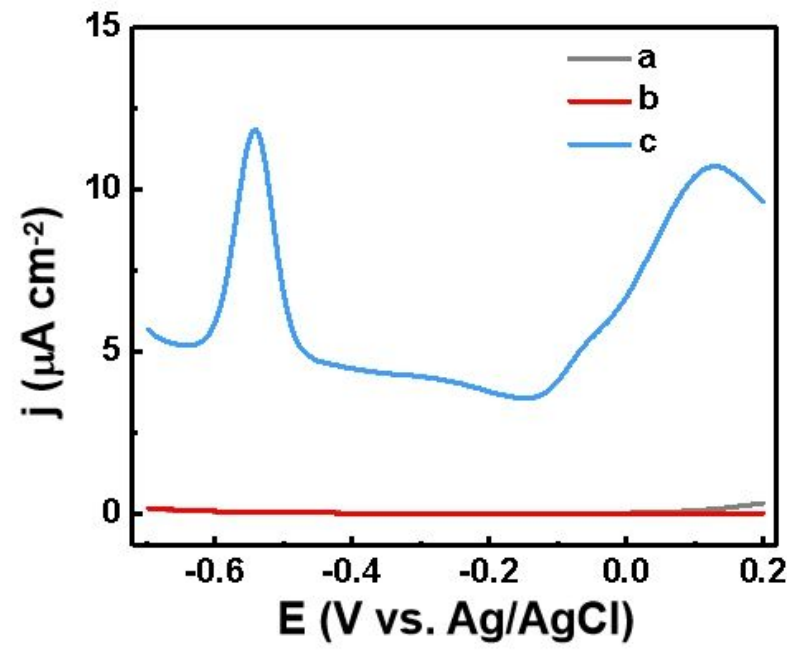

Figure S6. DPVs obtained at (a) CFME, (b) CFME/AQ+MBS, and (c) CFME/ERGO-CNT/AQ+MBS in $0.1 \mathrm{M}$ PBS (pH 7.0) containing $1 \mathrm{mM}$ AA, respectively.

9. DPVs obtained at CFME/ERGO-CNT/AQ.

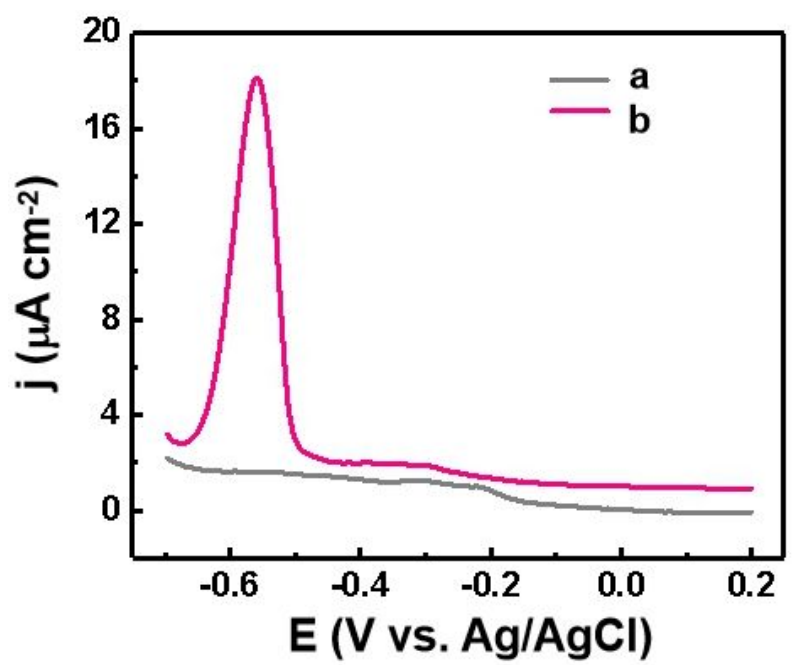

Figure S7. DPVs obtained at CFME/ERGO-CNT (a) and CFME/ERGO-CNT/AQ (b) in blank PBS (0.1 M, pH 7.0), respectively. 
10. UV-Vis absorption spectral response of probe MBS to HClO.

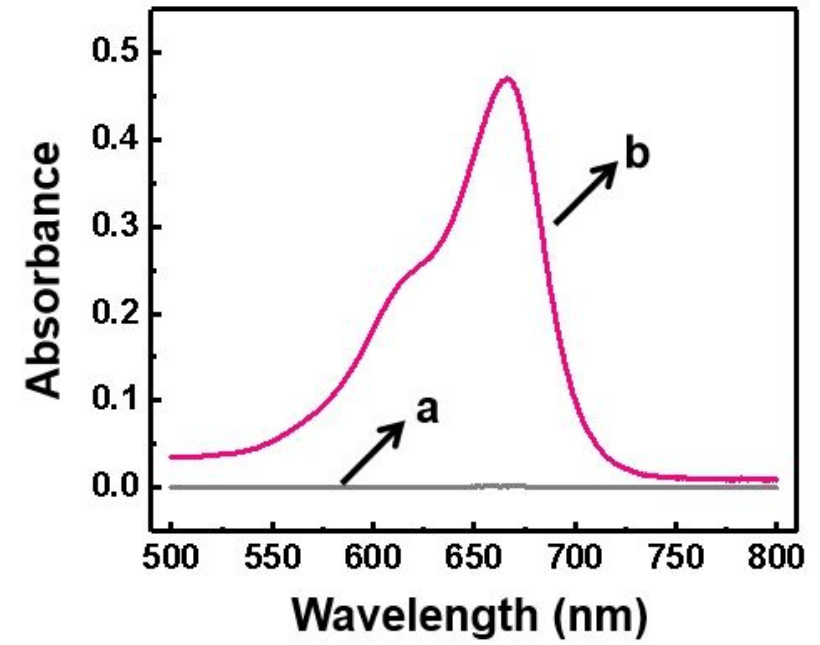

Figure 8. (A) UV-Vis absorption of MBS $(5 \mu \mathrm{M})$ before (a) and after reaction with $\mathrm{HClO}(50 \mu \mathrm{M})$ (b) for $2 \mathrm{~min}$. The inset shows the corresponding colour change of MBS before and after reaction.

11. Response time.

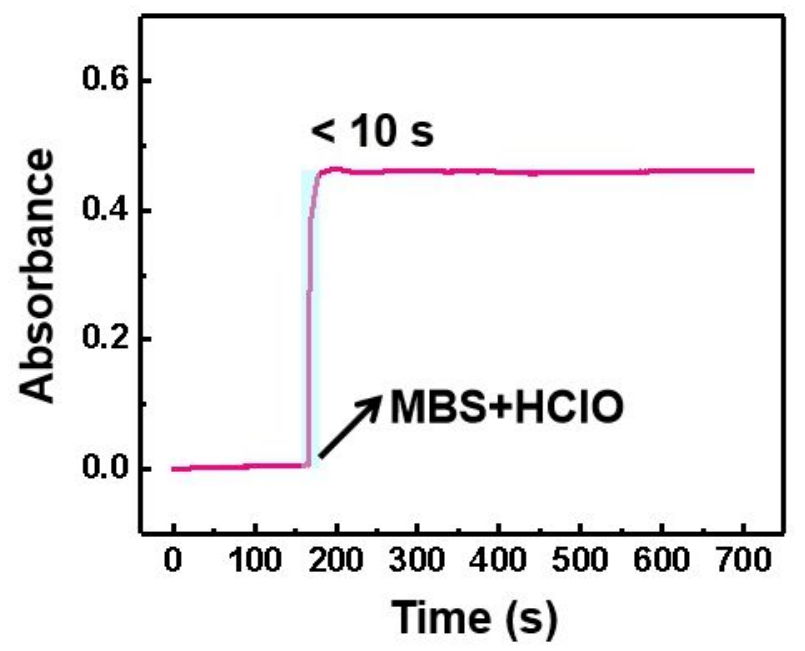

Figure S9. Time dependent UV-Vis absorption response of MBS $(5 \mu \mathrm{M})$ to $\mathrm{HClO}(50 \mu \mathrm{M})$ in 0.1 M PBS solution ( $\mathrm{pH} 7.0)$. 
12. Liquid chromatography.

A

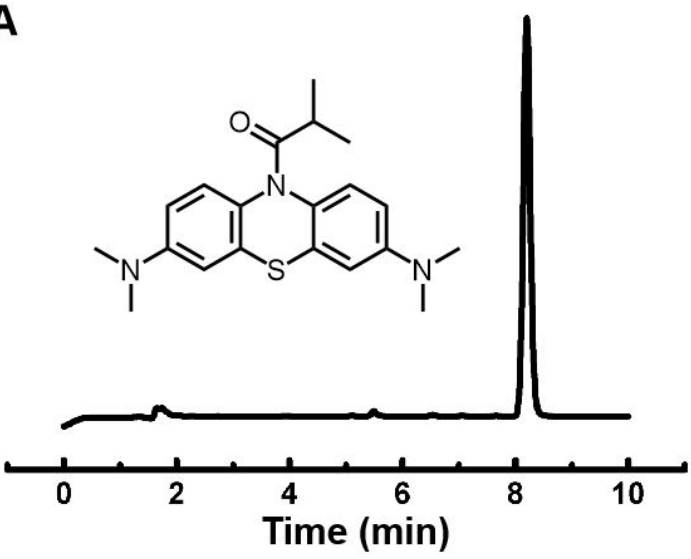

B

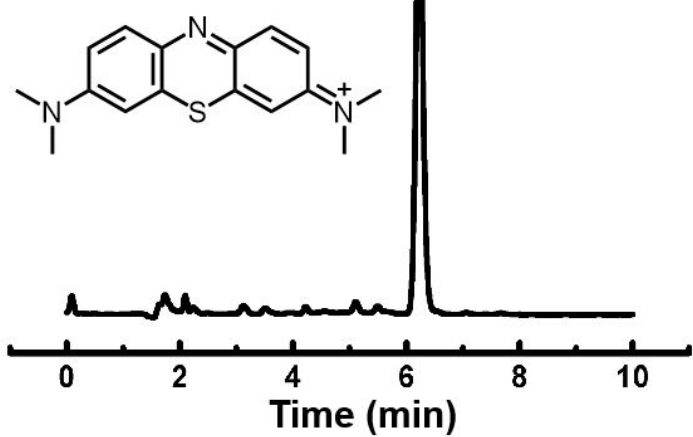

Figure S10. HPLC analysis of MBS (A) and the products of the reaction between $5 \mu \mathrm{M}$ MBS solution and $50 \mu \mathrm{M} \mathrm{HClO}(\mathrm{B})$, respectively.

\section{Mass spectra of MB.}

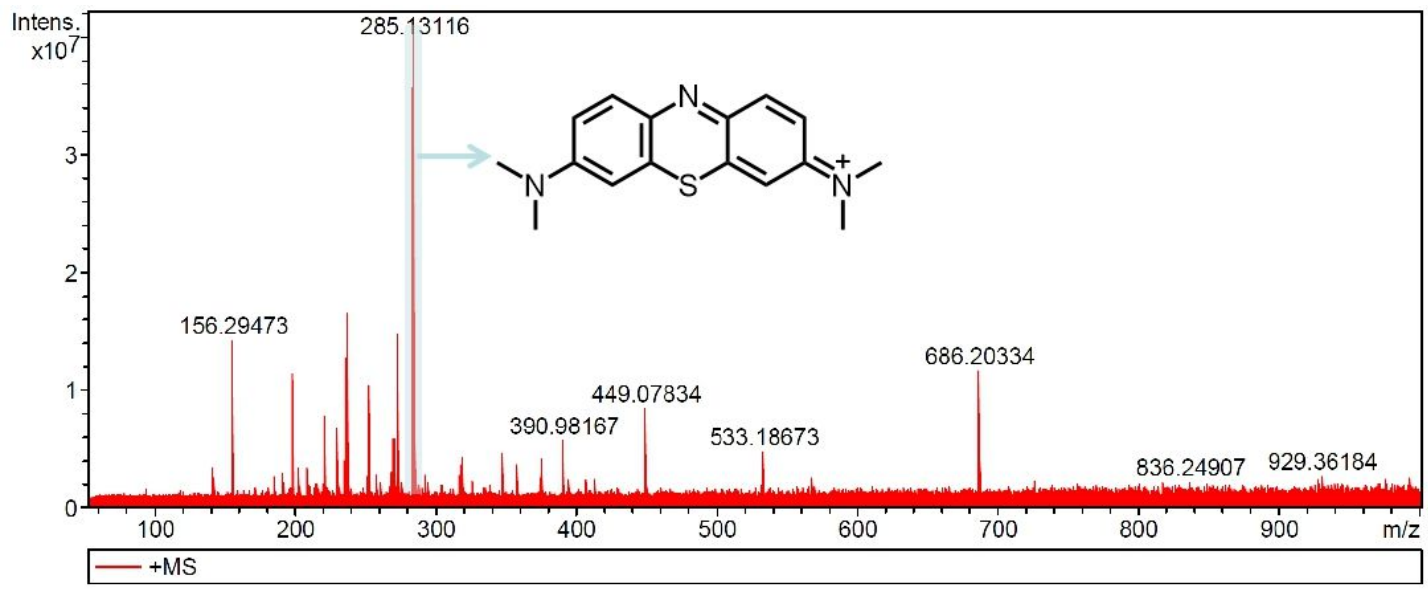

Figure S11. HRMS of the products of the reaction between $5 \mu \mathrm{M}$ MBS solution and $50 \mu \mathrm{M}$ $\mathrm{HClO}$. 
14. Reaction mechanism of MBS and HClO.<smiles>CC(C)C(=O)[O-]</smiles>

B<smiles>CN(C)c1ccc2c(c1)Sc1cc(N(C)C)ccc1N=C2</smiles>

Figure S12. (A) The chemical reaction between MBS and HClO. (B)The electrochemical reaction process of MB.

15. DPVs obtained at CFME/ERGO-CNT/MBS.

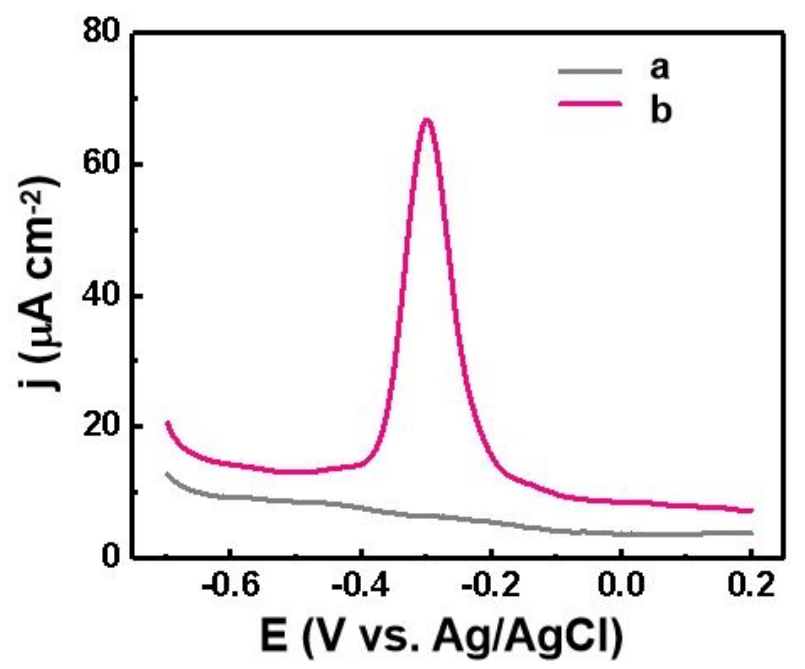

Figure S13. DPVs obtained at CFME/ERGO-CNT/MBS in blank PBS (0.1 M, pH 7.0) (a) and in the presence of $50 \mu \mathrm{M} \mathrm{HClO}(\mathrm{b})$, respectively.

16. Comparison of DPV responses of different modified electrodes to AA and 
HClO.

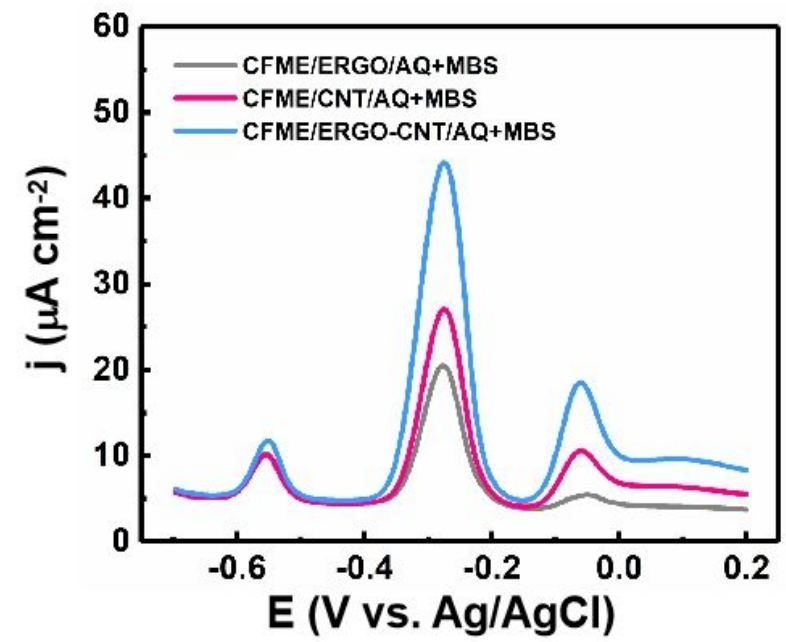

Figure S14. DPV responses of the different modified electrodes in 0.1 M PBS (pH 7.0) containing $1.0 \mathrm{mM}$ AA and $20 \mu \mathrm{M} \mathrm{HClO}$.

17. pH effect.
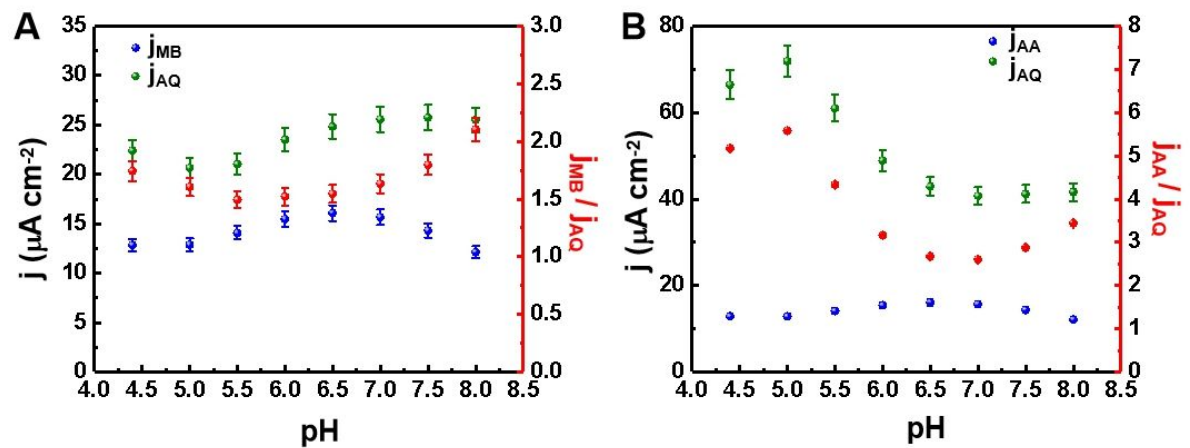

Figure S15. The relationship between the oxidation peak current densities ratio $\mathrm{j}_{\mathrm{MB}} / \mathrm{j}_{\mathrm{AQ}}(\mathrm{A})$, $\mathrm{j}_{\mathrm{AA}} / \mathrm{j}_{\mathrm{AQ}}(\mathrm{B})$ under different $\mathrm{pH}$ values, which are $4.4,5.0,5.5,6.0,6.5,7.0,7.5,8.0$, respectively.

\section{Scan rate.}



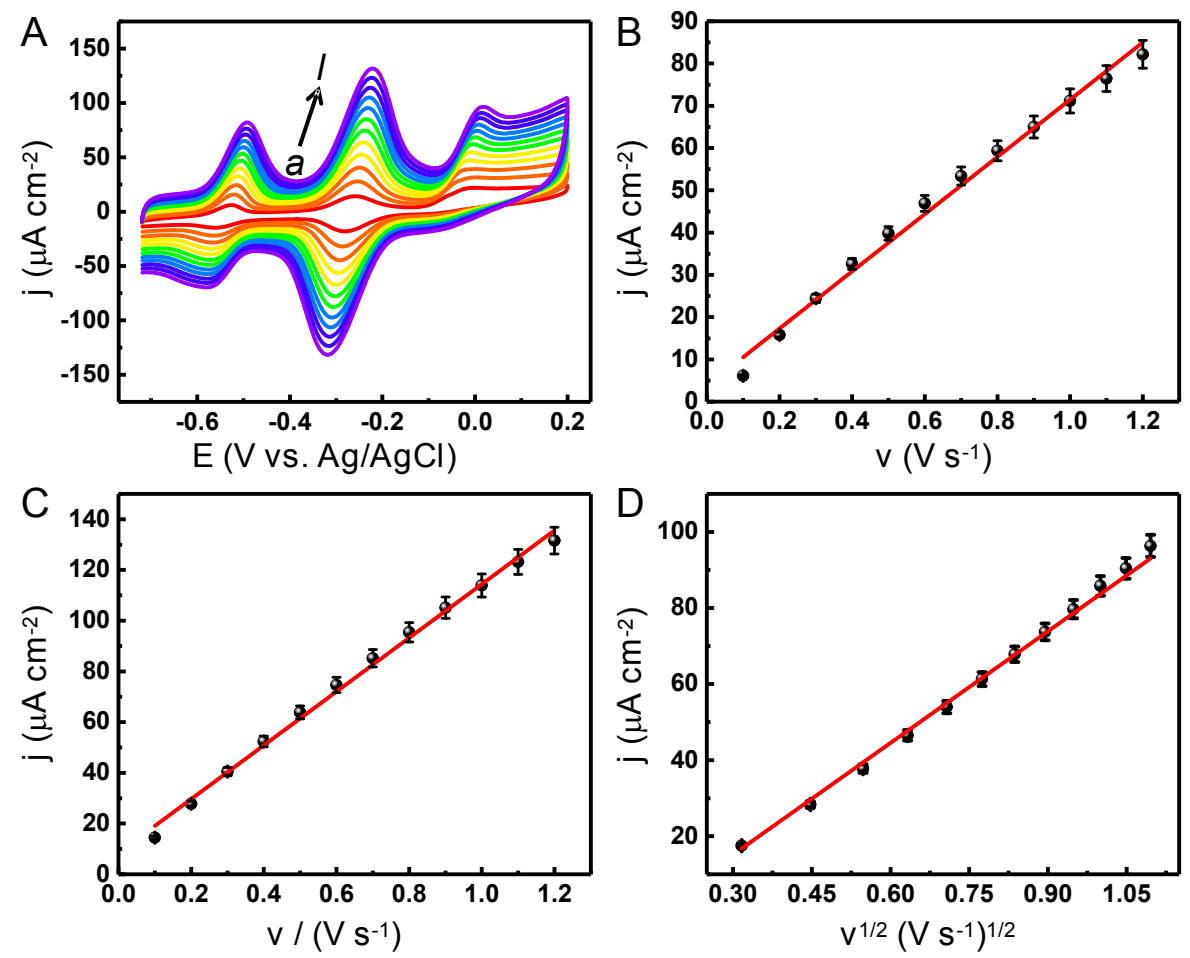

Figure S16. (A) CVs of a CFME/ERGO-CNT/AQ+MBS microelectrode in 0.1 M PBS (pH 7.0) obtained after the addition of $\mathrm{HClO}(20 \mu \mathrm{M})$ followed by AA $(1 \mathrm{mM})$. The CVs were acquired at scan rates of $0.10,0.20,0.30,0.40,0.50,0.60,0.70,0.80,0.90,1.0,1.1$, and $1.2 \mathrm{~V} \mathrm{~s}^{-1}$. Linear relationships between the oxidation peak current densities of (B) AQ, (C) MB, and (D) AA and the scan rate.

19. UV-Vis absorption spectral response of $\mathrm{AA}$ to $\mathrm{HClO}$.

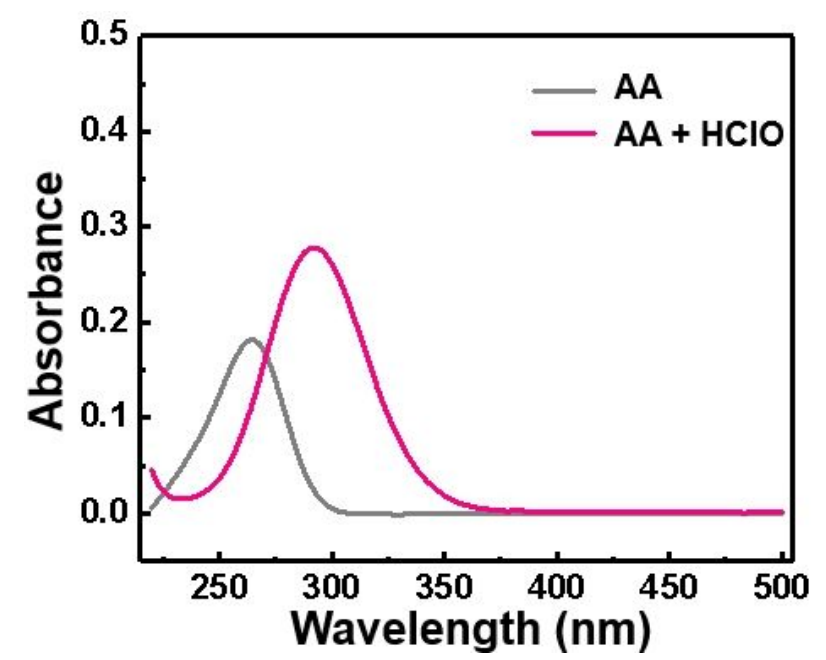

Figure S17. The UV-Vis absorbance spectra of AA $(200 \mu \mathrm{M})$ in $0.1 \mathrm{M}$ PBS buffer solution (pH 7.0) before and after adding $50 \mu \mathrm{M}$ of $\mathrm{HClO}$.

20. Time dependent $\mathrm{UV}-\mathrm{V}$ is absorption response of AA to $\mathrm{HClO}$. 


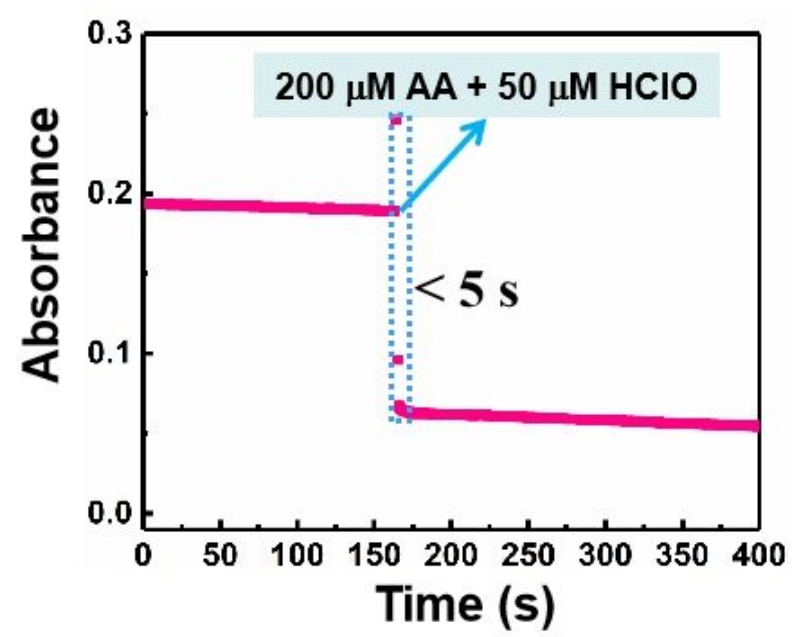

Figure S18. Time dependent UV-Vis absorption response of AA $(200 \mu \mathrm{M})$ to HClO $(50 \mu \mathrm{M})$ in 0.1 M PBS solution ( $\mathrm{pH} 7.0)$.

\section{Selectivity and competition tests for AA.}
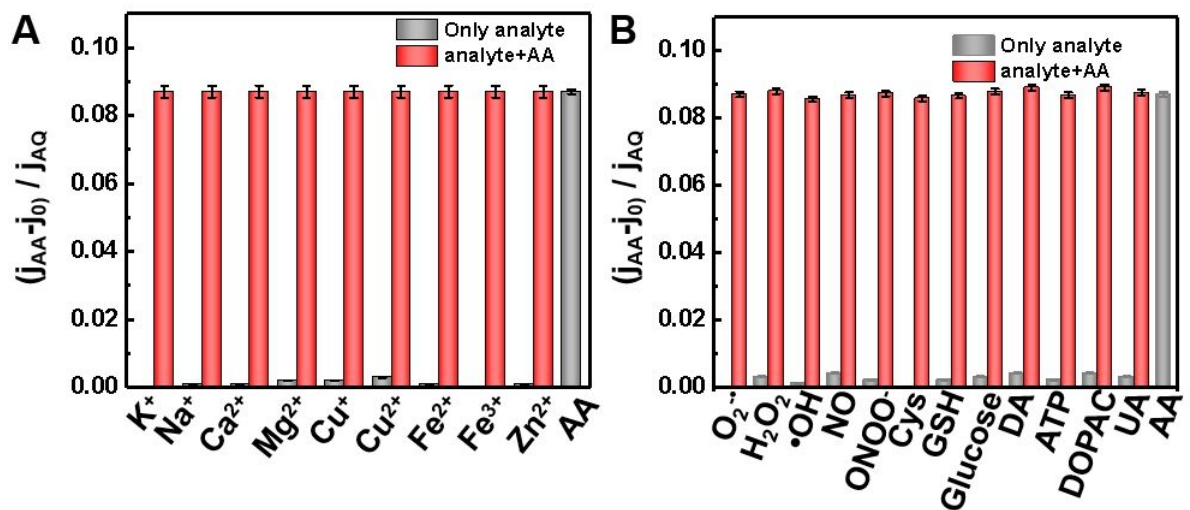

Figure S19. (A) Selectivity of the CFME/ERGO-CNT/AQ+MBS electrode for AA $(200 \mu \mathrm{M})$ in the presence of $100 \mathrm{mM} \mathrm{K}^{+}, 200 \mathrm{mM} \mathrm{Na}^{+}, 10 \mathrm{mM} \mathrm{Ca}^{2+}, 10 \mathrm{mM} \mathrm{Mg}^{2+}$, and $10 \mu \mathrm{M} \mathrm{Cu}^{+}, \mathrm{Cu}^{2+}, \mathrm{Fe}^{2+}$, $\mathrm{Fe}^{3+}$, and $\mathrm{Zn}^{2+}$. (B) Selectivity of the CFME/ERGO-CNT/AQ+MBS electrode for AA $(200 \mu \mathrm{M})$ in the presence of $50 \mu \mathrm{M} \mathrm{H}_{2} \mathrm{O}_{2}, 5 \mathrm{mM}$ glucose, $200 \mathrm{nM} \mathrm{DA}, 100 \mathrm{nM} \mathrm{ATP}$, and $10 \mu \mathrm{M} \mathrm{O}_{2}^{-\bullet} \cdot \mathrm{OH}$, NO, $\mathrm{ONOO}^{-}$, Cys, GSH, DOPAC, and UA. 
concentrations of $\mathrm{HClO}$.
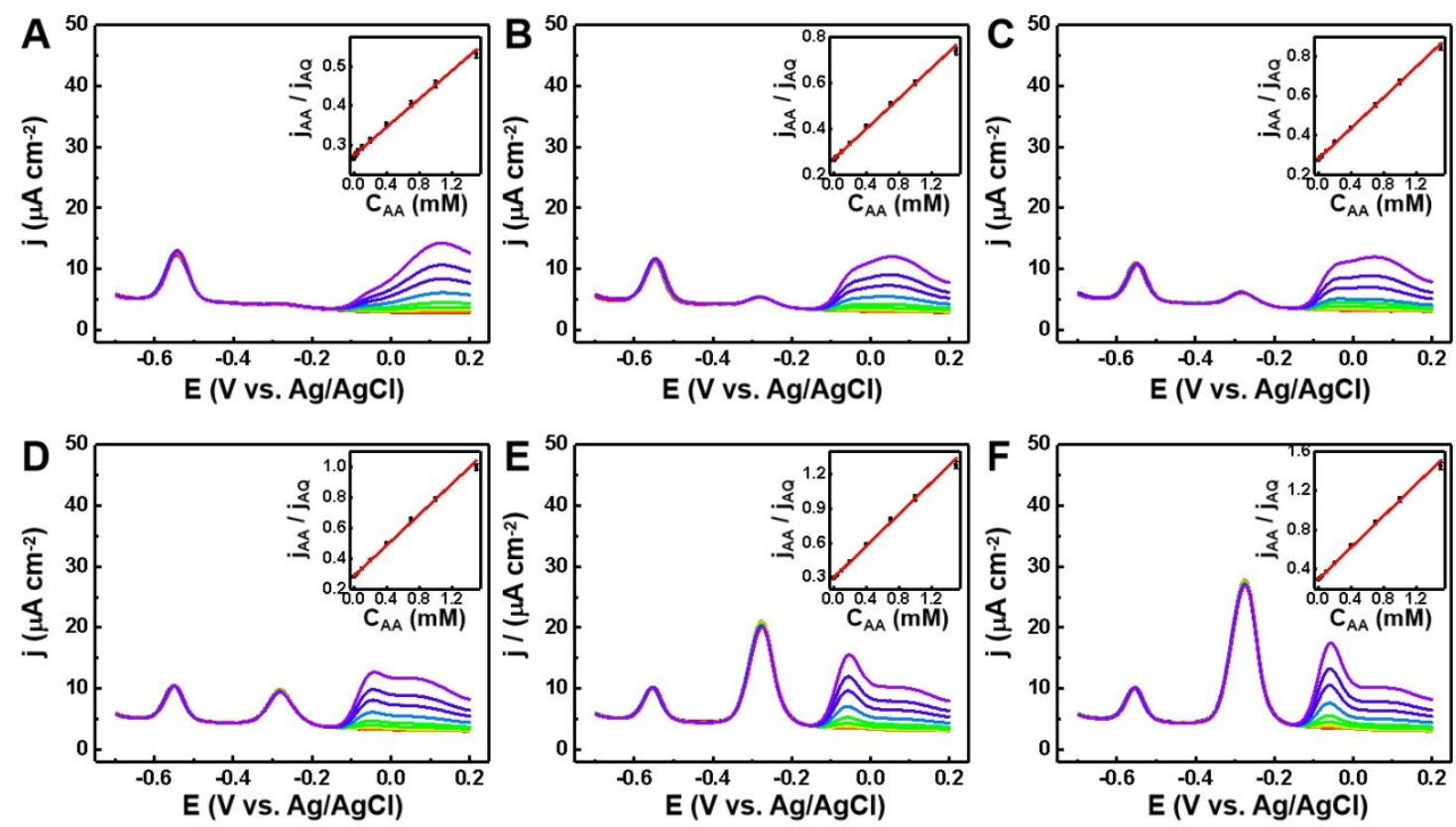

Figure S20. DPVs obtained at CFME/ERGO-CNT/AQ+MBS in $0.1 \mathrm{M}$ PBS (pH 7.0) for different concentrations of $\mathrm{HClO}$, (A) concentration of HClO: $1 \mu \mathrm{M}$. (B) concentration of HClO: $2 \mu \mathrm{M}$. (C) concentration of HClO: $4 \mu \mathrm{M}$. (D) concentration of HClO: $6 \mu \mathrm{M}$. (E) concentration of HClO: 10 $\mu \mathrm{M}$. (F) concentration of HClO: $20 \mu \mathrm{M}$. Inset: The linear relationship of $\mathrm{j}_{\mathrm{AA}} / \mathrm{j}_{\mathrm{AQ}}$ with different concentrations of AA (they are $0.01,0.03,0.05,0.10,0.20,0.40,0.70,1.00,1.50 \mathrm{mM}$ ).

\section{Contact angles.}
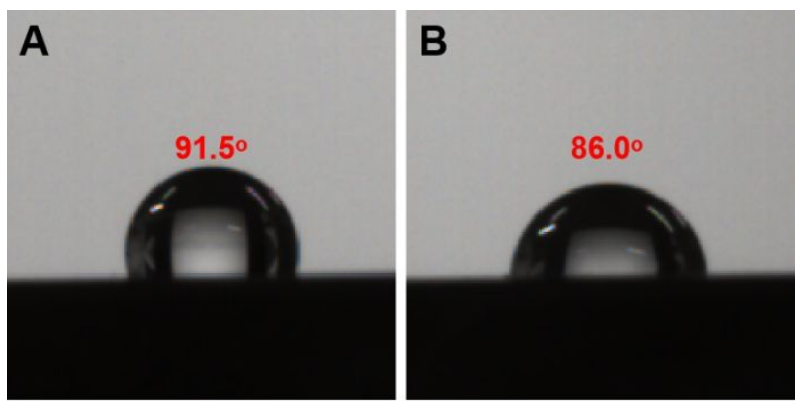

Figure S21. The contact angles obtained at the GCE/ERGO-CNT/MBS before (A) and after (B) reacting with $50 \mu \mathrm{M} \mathrm{HClO}$, respectively.

\section{Reproducibility and repeatability.}



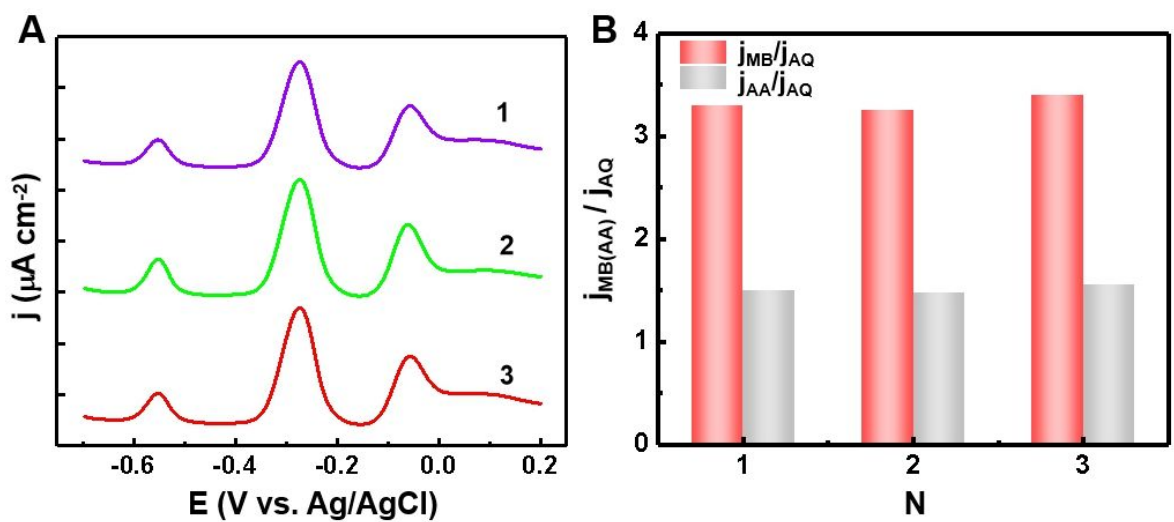

Figure S22. (A) Reproducibility test for three different CFME/ERGO-CNT/AQ+MBS electrodes in $0.1 \mathrm{M}$ PBS (pH 7.0) containing $20 \mu \mathrm{M} \mathrm{HClO}$ and $1.5 \mathrm{mM} \mathrm{AA}$. (B) Repeatability test for the same CFME/ERGO-CNT/AQ+MBS electrode in $0.1 \mathrm{M}$ PBS (pH 7.0) containing $20 \mu \mathrm{M} \mathrm{HClO}$ and $1.5 \mathrm{mM}$ AA.

\section{Stability.}
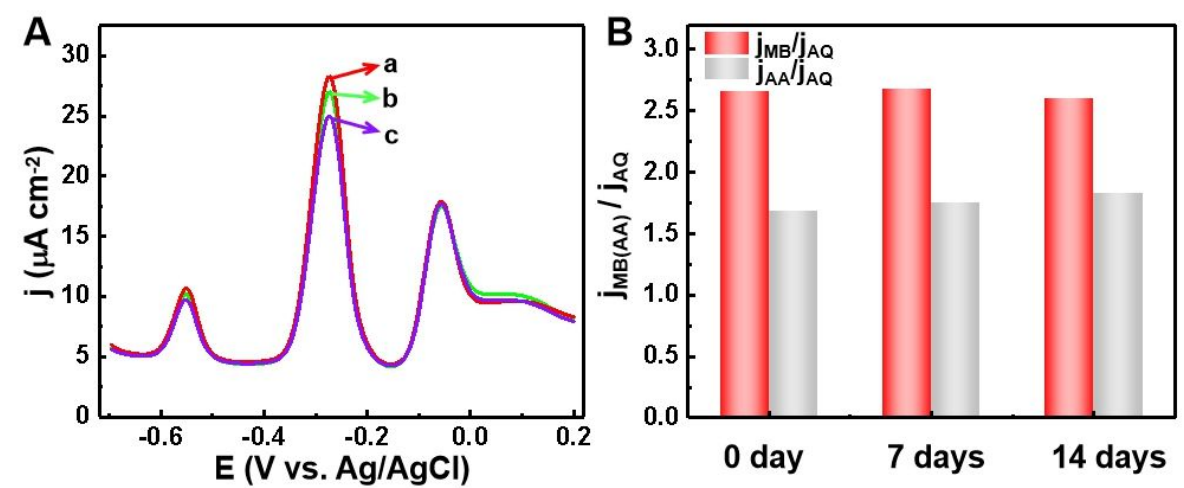

Figure S23. (A) The stability test for three different CFME/ERGO-CNT/AQ+MBS electrodes prepared as the same method in $0.1 \mathrm{M}$ PBS (pH 7.0) containing $20 \mu \mathrm{M} \mathrm{HClO}$ and $1.5 \mathrm{mM} \mathrm{AA}$ with different days.

26. Biocompatibility. 

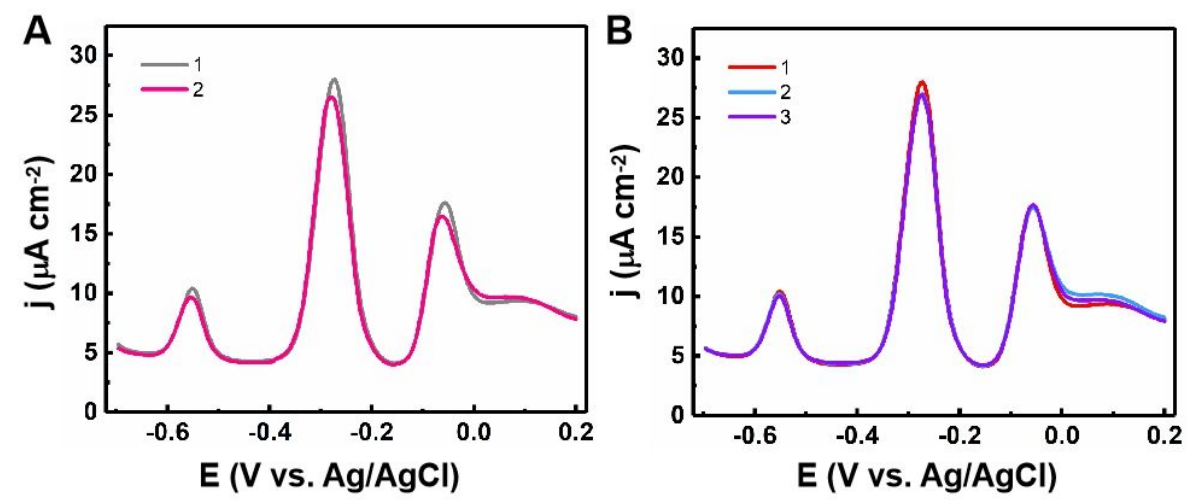

Figure S24. (A) DPVs obtained in absence (1) and presence (2) of $0.5 \%$ BSA in 0.1 M PBS (pH 7.0) containing $20 \mu \mathrm{M} \mathrm{HClO}$ and $1.0 \mathrm{mM}$ AA ( $\mathrm{pH} 7.0)$. (B) DPVs obtained in 0.1 M PBS (pH 7.0) and serum (10:1) containing $20 \mu \mathrm{M} \mathrm{HClO}$ and 1.0 mM AA with three consecutive determinations (1-3).

Table S1. The concentrations of $\mathrm{HClO}$ and AA determined by the present method in Urine.

\begin{tabular}{|c|c|c|c|c|c|c|c|c|}
\hline \multirow[b]{2}{*}{ Sample } & \multicolumn{4}{|c|}{$\mathrm{HClO}$} & \multicolumn{4}{|c|}{$\mathrm{AA}$} \\
\hline & $\begin{array}{c}\text { Spiked } \\
(\mu \mathrm{M})\end{array}$ & $\begin{array}{l}\text { Found } \\
(\mu \mathrm{M})\end{array}$ & $\begin{array}{c}\text { Recovery } \\
(\%)\end{array}$ & $\begin{array}{l}\text { RSD } \\
(\mathrm{n}=3)\end{array}$ & $\begin{array}{c}\text { Spiked } \\
(\mu \mathrm{M})\end{array}$ & $\begin{array}{l}\text { Found } \\
(\mu \mathrm{M})\end{array}$ & $\begin{array}{c}\text { Recovery } \\
(\%)\end{array}$ & $\begin{array}{l}\text { RSD } \\
(\mathrm{n}=3)\end{array}$ \\
\hline \multirow{4}{*}{ Urine } & 0 & 0 & & & 0 & 0 & & \\
\hline & 1.0 & 0.99 & 99.0 & 1.85 & 20.0 & 20.4 & 102.0 & 1.63 \\
\hline & 5.0 & 5.12 & 102.4 & 0.99 & 50.0 & 50.8 & 101.6 & 1.78 \\
\hline & 10.0 & 9.89 & 98.9 & 2.18 & 100.0 & 99.5 & 99.5 & 0.99 \\
\hline
\end{tabular}

Table S2. AA detection at CFME/ERGO-CNT/AQ+MBS electrode in human serum 
with AD.

\begin{tabular}{cccc}
\hline Sample no. & Type & $\begin{array}{c}\mathrm{C}_{\mathrm{AA}} / \mathrm{mM} \\
(\mathrm{n}=3)\end{array}$ & $\begin{array}{c}\mathrm{RSD} / \% \\
(\mathrm{n}=3)\end{array}$ \\
\hline 1 & $\mathrm{AD}$ & $35 \pm 4 \mu \mathrm{M}$ & 1.5 \\
2 & $\mathrm{AD}$ & $30 \pm 4 \mu \mathrm{M}$ & 2.0 \\
3 & $\mathrm{AD}$ & $38 \pm 3 \mu \mathrm{M}$ & 1.4 \\
\hline
\end{tabular}

Table S3. The concentrations of $\mathrm{HClO}$ and AA determined by the present method in saliva.

\begin{tabular}{ccccccccc}
\hline & \multicolumn{3}{c}{ HClO } & \multicolumn{3}{c}{ AA } \\
Sample & Spiked & Found & Recovery & RSD & Spiked & Found & Recovery & RSD \\
$(\mu \mathrm{M})$ & $(\mu \mathrm{M})$ & $(\%)$ & $(\mathrm{n}=3)$ & $(\mu \mathrm{M})$ & $(\mu \mathrm{M})$ & $(\%)$ & $(\mathrm{n}=3)$ \\
\hline \multirow{2}{*}{ Saliva } & 1.0 & 1.02 & 102.0 & 1.98 & 20.0 & 19.7 & 98.5 & 2.04 \\
& 5.0 & 4.85 & 97.0 & 0.99 & 50.0 & 48.6 & 97.2 & 2.32 \\
& 10.0 & 10.20 & 102.0 & 1.55 & 100.0 & 102.5 & 102.5 & 1.74 \\
\hline
\end{tabular}

\section{REFERENCE}

(1) Peng, T.; Wong, N.; Chen, X.; Chan, Y.; Ho, D. H.; Sun, Z.; Hu, J. J.; Shen, J.; El-Nezami, H.; Yang, D. J. Am. Chem. Soc. 2014, 136, 11728-11734.

(2) Dong, H.; Zhou, Q.; Zhang, L.; Tian, Y. Angew. Chem. Int. Edit. 2019, 58, 13948-13953.

(3) Liu, F.; Dong, H.; Tian, Y. Analyst 2019, 144, 2150-2157.

(4) Zhou, Y. , Dong, H. , Liu, L. , Liu, J. , \& Xu, M. Biosens. Bioelectro. 2014, 60, 231-236.

(5) Dong, H.; Zhou, Y.; Hao, Y.; Zhao, L.; Sun, S.; Zhang, Y.; Ye, B.; Xu, M. Biosens. Bioelectro. 2020, 165, 112402 . 